\title{
Review of social media intervention in adult population during COVID-19 pandemic based on Protection Motivation Theory
}

\author{
Muhammad Prima Cakra Randana ${ }^{1}$, Rizma Adlia Syakurah ${ }^{2}$ \\ ${ }^{1}$ Medical Faculty, Sriwijaya University, Palembang, Indonesia \\ ${ }^{2}$ Public Health Faculty, Sriwijaya University, Palembang, Indonesia
}

\begin{abstract}
Article Info
Article history:

Received Jan 14, 2021

Revised Jul 16, 2021

Accepted Aug 23, 2021

Keywords:

COVID-19

Opinion

Pandemic

PMT

Social media

ABSTRACT

During COVID-19 pandemic, social media has become a basis for information deployment, it has the potential to change people opinion and solve many issues in this situation. Based on Protection Motivation Theory (PMT), threat and coping appraisal were predictors to behavioral responses in pandemics. This study aimed to analyze the impact of social media intervention in adult population during COVID-19 pandemic based on PMT. This review was created using Preferred Reporting Items for Systematic Reviews and Meta-Analysis (PRISMA) and data collection from electronic databases such as Pubmed, Mendeley app, Europe PMC, Cochrane Databases, Science Direct, and Wiley Online Library. Inclusion criteria consists of English studies, studies related to the topic and match with required variables. There are five cross-sectional studies involving a total of 2.448 participants that were published in 2020. Among all categories based on included studied, it was shown that cyberchondria, perceived severity and perceived vulnerability are predictors in social media, related to behavioral responses during COVID-19 pandemic. Reducing information overload, related to cyberchondria, via the clear structuring and communication of reliable health information is needed. Hence, educating people on responsible and healthy social media use could help alleviate the observed negative consequences from perceived severity and vulnerability.
\end{abstract}

This is an open access article under the CC BY-SA license.

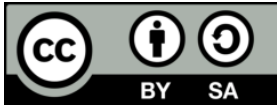

\section{Corresponding Author:}

Rizma Adlia Syakurah

Public Health Faculty

Sriwijaya University, Indonesia

Jl. Raya Palembang-Prabumulih KM. 32 Indralaya, Ogan Ilir, 30662, Indonesia

Email: rizma.syakurah@gmail.com

\section{INTRODUCTION}

The COVID-19 outbreak begins in Wuhan, China, in the end of December 2019. It is quickly spread to some cities in China in a matter of time [1]. The World Health Organization (WHO) announced COVID19 as a public health emergency and international concern on 30 January 2020 [2]. The COVID-19 pandemic has made a global health problem that has had a big impact on the way people perceive world and everyday lives [3], [4].

COVID-19 has been labelled as emerging respiratory disease by WHO. At the onset of illness, common symptoms are fever, cough, and fatigue. Meanwhile sputum production, headache, haemoptysis, and diarrhoea are fewer common symptoms [5], [6]. Beside the COVID-19 has an effect on human's physical health, psychosocial aspect can be affected on general population including long-term health, isolation, and stigma [7]. Consideration regarding filtering while accepting types and sources of news and promoting psychological interventions that support worldwide communities [8]. 
People nowadays use social media to express their evaluations and feelings toward this pandemic. Social media has been a place to publish a lot of information and news about COVID-19, creating social media turn into biggest sources of information [9]. Because the information is related to how they feel, the social media use through pandemic of COVID-19 make people are very focuses on reading and digesting the information [10]. This information can influence the opinion of people due to their past experiences and beliefs [11]. Misinformation regarding COVID-19 that can spread quickly around the world is one of WHO declaration regarding spread of information through social media [12], [13].

For predictions about their future behavior, opinion data will supply a basis for concluding the meaning of opinions conducted by individuals and groups. A theoretical scheme involving three processes of social influence is presented. Mentioned as compliance, identification, and internalization that explain the process by people to adopt and expressing. When an individual receives predispose from another person or a group because he expects to achieve a favorable reaction from the other, compliance can be occurred. When an individual adopts behavior originated from another person or a group in case that this behavior is related with a satisfying self-defining relationship to this person or group, identification can be occurred. Lastly, while an individual accepts influence because his value system is congruent with the induced behavior, the internalization can be said to occur [14].

COVID-19 pandemic has already contributed many important aspects in a good or bad way, making new normal in everyday social life. People adaptation during the pandemic to prevent their chance of contracting the COVID-19, for example washing hands, keeping the distance, and wearing protective mask which has been proven medically [15]. Besides that, mental health of social media users can be affected and spread by few published information in the social media [16]. One of the most used theories to explain person-level attitude reaction health-threatening situations such as COVID-19 pandemics is Protection Motivation Theory (PMT) [17]. Threat and coping appraisal were predictors of protection motivation of COVID-19 related behavioral responses [18]. Individual's perception of the vulnerability and seriousness in the pandemic situation is called as threat appraisal. Moreover, individual's evaluation of how well they can manage in the pandemic for example self-efficacy and response efficacy is mentioned as coping appraisal. To provide these research gap, cyberchondria and information overload as internet-specific construct as one of the needed variables by the authors.

Social media has been a source of deployment to general public during these COVID-19 pandemic that become a reason why it has a potential to change people perception even solve many issues in this condition. A third of online users in worldwide were aged among 25 until 34 years, according to Statista $\odot$ in 2019. Social media users in this range are the biggest group of online users globally. The behavior of consuming information from social media and then easily applying to their family of friends improve at younger age group [19]. So that, a purpose of study is analyzing the impact of social media intervention in adult population through COVID-19 pandemic based on PMT.

\section{RESEARCH METHOD}

The study was created according to guidelines of Preferred Reporting Items for Systematic Reviews and Meta-Analysis (PRISMA). Pandemic just happen in early 2020 so there are only several studies related to COVID-19, in consequence there was no limitations in publication while looking for and collecting data. The studies were collected from electronic databases such as Pubmed, Mendeley app, Europe PMC, Cochrane Databases, Science Direct, and Wiley Online Library using keyword "social media intervention" or "social media use" and "opinion change" and "coronavirus" or "COVID-19". Only English language texts become consideration. Studies related to social media intervention through pandemic and suitable with determined variables that are populations of adult, social media intervention and COVID-19 pandemic. Incomplete data and non-English studies become exclusion criteria in this study.

Literature searching was conducted in May 2020. Same article in various databases were removed from one set of the search results. Titles and abstracts were screened by authors divided into two groups. After screening for abstracts, the complete text of the remaining articles was screened along to include the articles within the review. The articles chosen from the screening method were analyzed by the authors for data extraction, and the findings were discussed between the groups of researchers. The data extraction table is then used to extract the characteristics of each study and the main findings, which include the author, year of publication, country, study design, sample size, sample age range, sample sex, level of education, social media platforms and major findings. 


\section{RESULTS AND DISCUSSION}

There were 66 studies identified through searching various databases such as Pubmed, Mendeley app, Europe PMC, Cochrane Databases, Science Direct, and Wiley Online Library, of which 49 were excluded after screening for duplication, title and abstract, leaving 17 potentially relevant studies to be retrieved for full-text assessment. Among the 17 remaining studies, 12 were excluded due to either nonEnglish studies, incomplete data or irrelevant topics. The authors include five studies that were found to match the inclusion criteria for the systematic review as shown in Figure 1.

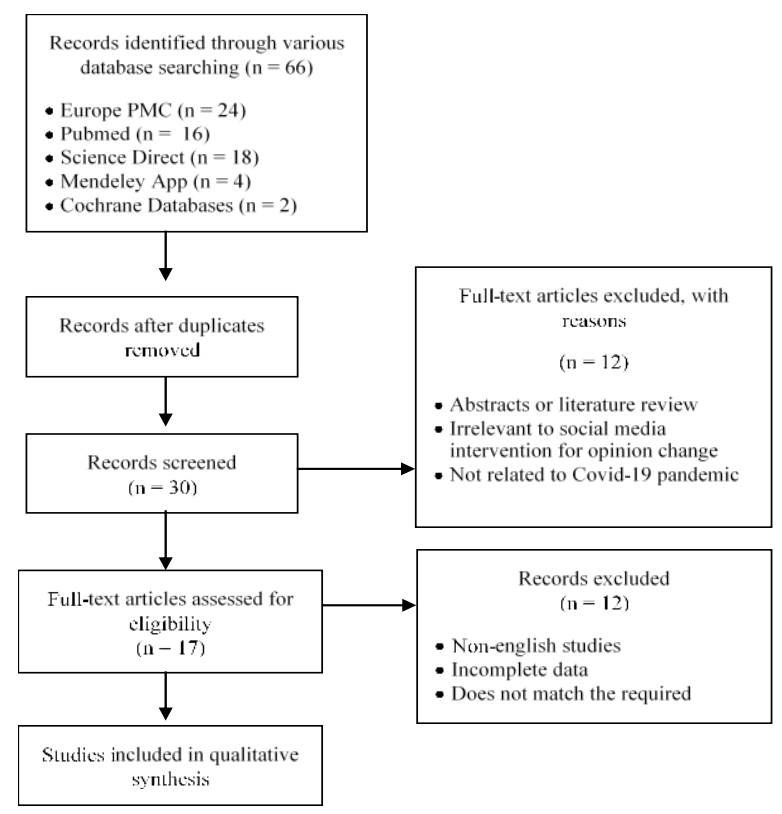

Figure 1. Flow diagram of the screening and selection process of the article

There are five cross-sectional studies involving a total of 2,448 participants that were published in 2020. These studies were conducted in Iraqi Kurdistan, Jordan, Finland, Egypt and India. Out of five studies, there are four studies shared similar demographic characteristics being predominantly female (51.2-78.6\%) and level of education as university graduate (50.6-90\%). The age of sample ranges from 18-29 years old, which categorized as an adult. Only one study provided data about social media platforms used in the study, that is Facebook $(82.6 \%)$ as shown in Table 1 [9].

Table 1. Characteristic of studies

\begin{tabular}{|c|c|c|c|c|c|c|c|c|}
\hline No & Study & Country & Design & $\begin{array}{l}\text { Sample } \\
\text { size (n) }\end{array}$ & $\begin{array}{l}\text { Age range in } \\
\text { years }(\%)\end{array}$ & $\operatorname{Sex}(\%)$ & $\begin{array}{c}\text { Level of } \\
\text { education }(\%)\end{array}$ & $\begin{array}{c}\text { Social } \\
\text { media } \\
\text { platforms } \\
(\%) \\
\end{array}$ \\
\hline 2 & $\begin{array}{c}\text { Karasneh et } \\
\text { al. }[20]\end{array}$ & Jordan & $\begin{array}{c}\text { Cross } \\
\text { sectional }\end{array}$ & 486 & $\leq 25(36.8 \%)$ & $\begin{array}{c}\text { Female }(78.6 \%) \\
\text { Male }(21.4 \%) \\
\text { Female }(65.3 \%)\end{array}$ & $\begin{array}{c}\text { Bachelor } \\
(52.1 \%)\end{array}$ & N/A \\
\hline 3 & $\begin{array}{c}\text { Farooq et } \\
\text { al. }[21]\end{array}$ & Finland & $\begin{array}{c}\text { Cross } \\
\text { sectional }\end{array}$ & 225 & $\leq 25(39.5 \%)$ & $\begin{array}{c}\text { Male }(32.4 \%) \\
\text { Prefer not to tell } \\
\quad(2.2 \%)\end{array}$ & N/A & N/A \\
\hline 4 & $\begin{array}{l}\text { Abdelhafiz } \\
\text { et al. }[22]\end{array}$ & Egypt & $\begin{array}{c}\text { Cross } \\
\text { sectional }\end{array}$ & 559 & $\begin{array}{c}18-29 \\
(48.1 \%)\end{array}$ & $\begin{array}{c}\text { Female }(62.3 \%) \\
\text { Male }(37.7 \%)\end{array}$ & $\begin{array}{l}\text { University } \\
(52.2 \%)\end{array}$ & N/A \\
\hline 5 & $\begin{array}{c}\text { Roy et al. } \\
\text { [23] }\end{array}$ & India & $\begin{array}{c}\text { Cross } \\
\text { sectional }\end{array}$ & 662 & $29.09 \pm 8.83$ & $\begin{array}{c}\text { Female }(51.2 \%) \\
\text { Male }(48.6 \%)\end{array}$ & $\begin{array}{c}\text { Graduation } \\
(90 \%)\end{array}$ & N/A \\
\hline
\end{tabular}

Major findings were grouped into six categories that are information overload, cyberchondria, perceived severity, perceived vulnerability, and self-efficacy and responses efficacy. Based on the evidence of the review, it was shown that cyberchondria, perceived severity and perceived vulnerability are most things in social media that explain individual-level behavioral responses in pandemic as shown in Table 2.

Review of social media intervention in adult population during... (Muhammad Prima Cakra Randana) 
Table 2. The impact of social media intervention in adult population during COVID-19 pandemic based on

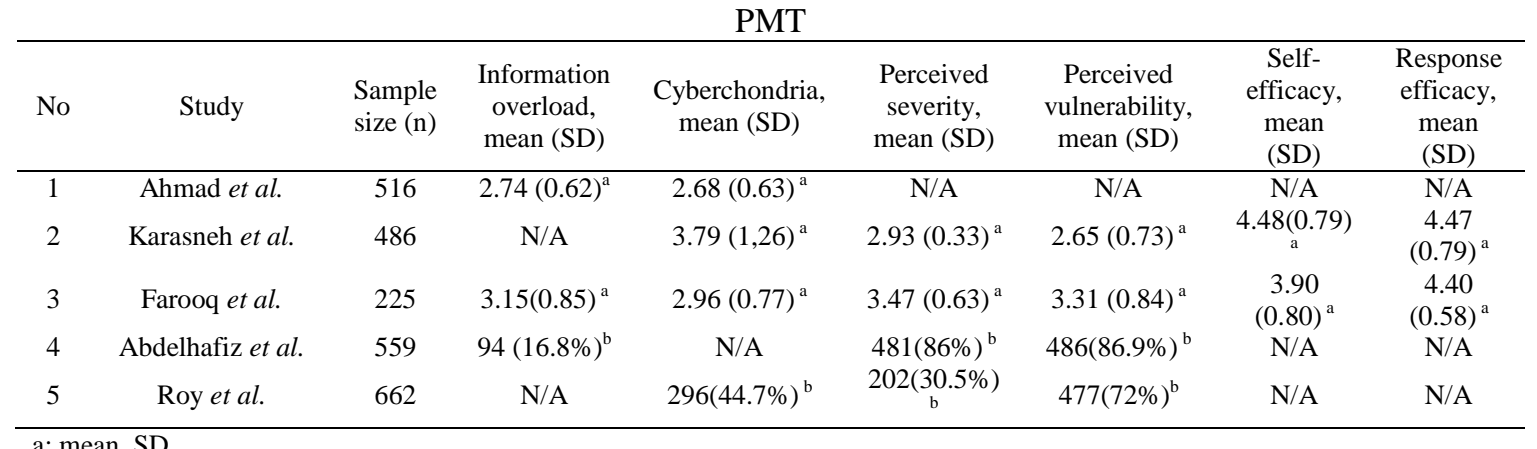

b: $n, \%$

\subsection{Cyberchondria}

An obsessive online investigate for health information, commonly regarding certain symptoms which is called as cyberchondria [24]. Cyberchondria term is originated from the name "cyber" and "hypochondriasis", it is shape of hypochondriasis link to each other with the internet or personal computer use, even induced by it [25], [26]. At times of insurance such as the current pandemic, an increased number of cases of cyberchondria should be predicted to appear. New worries could be triggered by cyberchondria because new disease sign and symptoms that they found online with similar scared individuals [27], [28]. Stress or physical problem which caused by mental distress for who did exaggerated or recurring healthrelated search on their internet, will only become more depressed or scare [29], [30].

Though negative framing is usually referring to cyberchondria, in this pandemic situation it possibly has assisted related to understand the real severity of COVID-19 condition for public [31], [32]. Misinformation incidence can be reduced by choosing credible official social media, for example from government account [33]. The government of India has asked famous social media platform such as Facebook, YouTube, TikTok, ShareChat and Twitter to publish right information, as it can decrease panic among people [34], [35].

Other study also supported the findings on this review which presented people's motivation in adopting recommended health measures during cyberchondria [36]. Third of those who conducted healthrelated internet search was reported as cyberchondria with background of old age and previously had health anxiety [37]. Cyberchondria can be increased by perceived severity and perceived susceptibility which categorized as health belief factors [38].

\subsection{Perceived severity}

The most important factor which perhaps lead to PMT is perceived severity[39]-[42]. The perceived severity of the given situation is expected to be increased, in reason that concern for specific health issues or symptoms fuel cyberchondria. Additionally, perceived severity generally is caused negative effect of unsavory health-related consequences regarding community's subjective [43], [44]. Threat appraisal component such as perceived severity and sensitivity in the other study were minor prediction of PMT during A/H1N1 pandemic [45], [46].

\subsection{Perceived vulnerability}

Increasing of taken health measures can been found during perceived vulnerability [47]. When people face of perceive health-related risks, they feels worry, concern, or dread about the disease as of people incline to find out at the worst and fearful report first, especially on online search [21], [43]. Several previous studies have shown an increase in public searches related to the COVID-19 pandemic from various factors [48]-[50]. Studies of Europe, Malaysia, UK, and The Netherlands showed that individuals who perceived themselves to be at risk were more likely to motivate for protection. Low level of appraised threat of COVID-19 pandemic might prevent motivation of healthcare professional to participate in protective behavior [46]. Meanwhile, in previous meta-analysis the influence sizes of such two items were minor to middle and barely expected of protection motivation also behavior if contrasted to the items of response efficacy and self-efficacy [17], [51]. 


\subsection{Limitations}

Limitations of this systematic review also present which is necessary to be taken into account. First and foremost, a data which collected was a cross-sectional so that did not too valid for any modification through time. For instance, it is a fact that overload of information was felt greater at the started of COVID19 pandemic while unspecific of situation were heavier. Secondly, the participants were chosen from a limited area geographically and socially. Through the collection of data time, there was a shortage of references regarding COVID-19 and social media, it makes this study depends on fresh researches which is ready. We consider that it has significance for increasing reliability which could be increased from data collection from other nations, particularly those that have been affected hardly by COVID-19 pandemic. Thirdly small number of studies is included in this research. Therefore, better design for next research is required to supply more credible outcome. Lastly, more than one article did not provide three variables which is information overload, response-efficacy, and self-efficacy.

\section{CONCLUSION}

Simultaneously increasing and intertwined in activities response of public health crisis. The function to directly communicate health information to public that provided by social media. Out of the six determinants provided in this study, it was shown that cyberchondria, perceived severity and perceived vulnerability are most things in social media that explain individual-level behavioral responses in pandemic.

Requirement of clear structuring and communication of trusted health information as the effort to decreasing information overload. Side effect of a severe global pandemic of COVID-19 may be raised such as cyberchondria can be alleviated. Consequently, promoting a lesson to people on use of social media responsibly and healthy can decreasing monitored negative consequence form perceived severity and vulnerability.

\section{REFERENCES}

[1] J. T. Wu, K. Leung, and G. M. Leung, "Nowcasting and forecasting the potential domestic and international spread of the 2019-nCoV outbreak originating in Wuhan, China: a modelling study," Lancet, vol. 395, no. 10225, pp. 689697, 2020, doi: 10.1016/S0140-6736(20)30260-9.

[2] World Health Organization, "WHO Director-General's statement on IHR Emergency Committee on Novel Coronavirus (2019-nCoV)," 2020. [Online]. Available: https://www.who.int/director-general/speeches/detail/whodirector-general-s-statement-on-ihr-emergency-committee-on-novel-coronavirus-(2019-ncov) (accessed Jun. 15, 2020).

[3] S. A. Tabish, "COVID-19 Pandemic: the crisis and the longer-term perspectives COVID-19 Pandemic: the crisis and the longer-term perspectives," J. Cardiol. Curr. Res., vol. 13, no. 2, p. 41-44, 2020, doi: 10.15406/jccr.2020.13.00472.

[4] A. L. Pedrosa et al., "Emotional, Behavioral, and Psychological Impact of the COVID-19 Pandemic," Front. Psychol., vol. 11, no. October, pp. 1-18, 2020, doi: 10.3389/fpsyg.2020.566212.

[5] N. Chen et al., "Epidemiological and clinical characteristics of 99 cases of 2019 novel coronavirus pneumonia in Wuhan, China: a descriptive study," Lancet, vol. 395, no. 10223, pp. 507-513, 2020, doi: 10.1016/S01406736(20)30211-7.

[6] W. Guan et al., "Clinical Characteristics of Coronavirus Disease 2019 in China," The new Engl. J. Med., vol. 382, no. 18, pp. 1708-1720, 2020, doi: 10.1056/NEJMoa2002032.

[7] J. Torales, M. O. Higgins, J. M. Castaldelli-maia, and A. Ventriglio, "The outbreak of COVID-19 coronavirus and its impact on global mental health," Int. J. Soc. Psychiatry, vol. 66, no. 4, pp. 3-6, 2020, doi: $10.1177 / 0020764020915212$.

[8] K. Shah, D. Kamrai, H. Mekala, B. Mann, K. Desai, and R. S. Patel, "Focus on Mental Health During the Coronavirus (COVID-19) Pandemic: Applying Learnings from the Past Outbreaks," Cureus, vol. 12, no. 3, 2020, doi: $10.7759 /$ cureus.7405.

[9] N. Pappot and H. Pappot, "Telemedicine and e-Health Solutions for COVID-19: Patients' Perspective," Telemed. eHEALTH, vol. 26, no. 7, pp. 10-12, 2020, doi: 10.1089/tmj.2020.0099.

[10] V. Sevilla, "Social media and community in pandemic COVID-19," Glob. Komunika J. Ilmu Sos. dan Ilmu Polit., vol. 1, no. 3, pp. 18-23, 2020.

[11] A. Mian and S. Khan, "Coronavirus : the spread of misinformation," BMC Med., vol. 18, no. 89, pp. 18-19, 2020, doi: 10.1186/s12916-020-01556-3.

[12] A. Wongkoblap, M. A. Vadillo, and V. Curcin, "Researching Mental Health Disorders in the Era of Social Media : Systematic Review," J. Med. Internet Res., vol. 19, no. 6, pp. 1-17, 2017, doi: 10.2196/jmir.7215.

[13] A. Gough et al., "Tweet for Behavior Change: Using Social Media for the Dissemination of Public Health Messages," JMIR Public Heal. Surveill., vol. 3, no. 1, pp. 1-17, 2017, doi: 10.2196/publichealth.6313.

[14] P. S. Adler and C. Xiaoling, "Combining creativity and control: Understanding individual motivation in large-scale collaborative creativity,” Accounting, Organ. Soc., vol. 36, no. 2, pp. 63-85, 2011, doi: 10.1016/j.aos.2011.02.002.

[15] A. Remuzzi and G. Remuzzi, "COVID-19 and Italy: what next?" Lancet, vol. 395, no. 10231, pp. 1225-1228, 
2020, doi: 10.1016/S0140-6736(20)30627-9.

[16] K. Hao and T. Basu, "The coronavirus is the first true social-media 'infodemic," MIT Technology Review, 2020. https://www.technologyreview.com/2020/02/12/844851/the-coronavirus-is-the-first-true-social-media-infodemic/ (accessed May 11, 2020).

[17] P. Bubeck, W. J. W. Botzen, and J. C. J. H. Aerts, "A Review of Risk Perceptions and Other Factors that Influence Flood Mitigation Behavior Perceptions and Private," Risk Anal. An Int. J., vol. 32, no. 9, pp. 1481-1495, 2012, doi: 10.1111/j.1539-6924.2011.01783.x.

[18] E. Teasdale, L. Yardley, W. Schlotz, and S. Michie, "The importance of coping appraisal in behavioural responses to pandemic flu," Br. J. Health Psychol., vol. 17, no. 1, pp. 44-59, 2012, doi: 10.1111/j.2044-8287.2011.02017.x.

[19] A. R. Ahmad and H. R. Murad, "The Impact of Social Media on Panic During the COVID-19 Pandemic in Iraqi Kurdistan: Online Questionnaire Study," J. Med. Internet Res., vol. 22, no. 5, pp. 1-11, 2020, doi: 10.2196/19556.

[20] R. Karasneh, S. Al-azzam, S. Mu, O. Soudah, and S. Hawamdeh, "Media's effect on shaping knowledge, awareness risk perceptions and communication practices of pandemic COVID-19 among pharmacists," Res. Soc. Adm. Pharm., vol. 17, no. 1, pp. 1897-1902, 2020, doi: 10.1016/j.sapharm.2020.04.027.

[21] A. Farooq, S. Laato, and A. K. M. N. Islam, "Impact of Online Information on Self-Isolation Intention During the COVID-19 Pandemic: Cross-Sectional Study,” J. Med. Internet Res., vol. 22, no. 5, pp. 1-15, 2020, doi: $10.2196 / 19128$.

[22] A. S. Abdelhafiz et al., "Knowledge, perceptions, and attitude of Egyptians towards the Novel Coronavirus Disease (COVID-19)," J. Community Health, vol. 45, no. 5, pp. 881-890, 2020, doi: 10.1007/s10900-020-00827-7.

[23] D. Roy, S. Tripathy, S. Kumar, N. Sharma, S. Kumar, and V. Kaushal, "Study of knowledge, attitude, anxiety \& perceived mental healthcare need in Indian population during COVID-19 pandemic," Asian J. Psychiatr., vol. 51, no. April, p. 102083, 2020, doi: 10.1016/j.ajp.2020.102083.

[24] T. A. Fergus and L. H. Russell, "Cyberchondria's Overlap with Health Anxiety and Obsessive-Compulsive Symptoms: An Examination of Latent Structure and Scale Interrelations," J. Anxiety Disord., vol. 38, no. March, pp. 88-94, 2016, doi: 10.1016/j.janxdis.2016.01.009.

[25] H. Zheng, S. J. Sin, H. K. Kim, and Y. Theng, "Cyberchondria : a systematic review," Internet Res., vol. 31, no. 2, pp. 677-698, 2020, doi: 10.1108/INTR-03-2020-0148.

[26] M. Vismara et al., "Is cyberchondria a new transdiagnostic digital compulsive syndrome? A systematic review of the evidence," Compr. Psychiatry, vol. 99, no. May, p. 152167, 2020, doi: 10.1016/j.comppsych.2020.152167.

[27] V. L. S. Tarcevic and E. L. A. Boujaoude, "Cyberchondria, cyberbullying, cybersuicide, cybersex: 'new' psychopathologies for the 21st century?" World Psychiatry, vol. 14, no. 3, pp. 97-100, 2015.

[28] A. M. Norr, B. J. Albanese, E. Mary, N. P. Allan, and N. B. Schmidt, "Anxiety sensitivity and intolerance of uncertainty as potential risk factors for cyberchondria," J. Affect. Disord., vol. 174, no. March, pp. 64-69, 2015, doi: $10.1016 / \mathrm{j} . j \mathrm{ad} .2014 .11 .023$.

[29] A. Loos, "Cyberchondria: Too much information for the health anxious patient?" J. Consum. Health Internet, vol. 17, no. 4, pp. 439-445, 2013, doi: 10.1080/15398285.2013.833452.

[30] V. Starcevic and D. Berle, "Cyberchondria: towards a better understanding of excessive health-related internet use," Expert Rev. Neurother., vol. 13, no. 2, pp. 205-213, 2013.

[31] V. La, T. Pham, M. Ho, and M. Nguyen, "Policy Response, Social Media and Science Journalism for the Sustainability of the Public Health System Amid the COVID-19 Outbreak: The Vietnam Lessons," Sustainability, vol. 12 , no. 7, p. 2931, 2020.

[32] S. Laato, A. K. M. N. Islam, M. N. Islam, and E. Whelan, "What drives unverified information sharing and cyberchondria during the COVID-19 pandemic ?," Eur. J. Inf. Syst., vol. 29, no. 3, pp. 288-305, 2020, doi: 10.1080/0960085X.2020.1770632.

[33] A. Gesser-Edelsburg, A. Diamant, R. Hijazi, and G. S. Mesch, "Correcting misinformation by health organizations during measles outbreaks : A controlled experiment," PLoS One, vol. 13, no. 12, p. e0209505, 2018.

[34] A. Depoux, S. Martin, E. Karafillakis, R. Preet, A. Wilder-Smith, and H. Larson, "The pandemic of social media panic travels faster than the COVID-19 outbreak," J. Travel Med., vol. 27, no. 3, p. 031, 2020, doi: $10.1093 / \mathrm{jtm} / \mathrm{taaa} 031$.

[35] M. Rafla, N. J. Carson, and S. M. Dejong, "Adolescents and the Internet: What Mental Health Clinicians Need to Know," Curr. Psychiatry Rep., vol. 16, no. 9, p. 472, 2014, doi: 10.1007/s11920-014-0472-x.

[36] N. Jokić-Begić, U. Mikac, D. Čuržik, and C. S. Jokić, "The Development and Validation of the Short Cyberchondria Scale (SCS)," J. Psychopathol. Behav. Assess., vol. 41, no. 4, pp. 662-676, 2019.

[37] D. Mohammed et al., "Cyberchondria: Implications of online behavior and health anxiety as determinants," Arch. Med. Heal. Sci., vol. 7, no. 2, pp. 154-162, 2019, doi: 10.4103/amhs.amhs_108_19.

[38] S. Laato, A. K. M. N. Islam, M. N. Islam, and E. Whelan, "Why do People Share Misinformation during the COVID-19 Pandemic?" arXiv Prepr. arXiv, no. April, 2020. [Online]. Available: https://arxiv.org/abs/2004.09600.

[39] S. Dryhurst, et al., "Risk perceptions of COVID-19 around the world," J. Risk Res., vol. 23, no. 7-8, pp. 994-1006, 2020, doi: 10.1080/13669877.2020.1758193.

[40] C. Rudisill, "How do we handle new health risks? Risk perception, optimism, and behaviors regarding the H1N1 virus," J. Risk Res., vol. 16, no. 8, pp. 959-980, 2013, doi: 10.1080/13669877.2012.761271.

[41] W. Van Der Weerd, D. R. M. Timmermans, D. J. M. A. Beaujean, J. Oudhoff, and J. E. van Steenbergen, "Monitoring the level of government trust, risk perception and intention of the general public to adopt protective measures during the influenza A (H1N1) pandemic in the Netherlands," BMC Public Health, vol. 11, no. 1, pp. 1$12,2011$.

Int. J. Public Health Sci., Vol. 10, No. 4, December 2021 : 843 - 849 
[42] T. Wise, T. D. Zbozinek, G. Michelini, C. C. Hagan, D. Mobbs, and T. Wise, "Changes in risk perception and selfreported protective behaviour during the first week of the COVID-19 pandemic in the United States," R. Soc. Open Sci., vol. 7, no. 9, p. 200742, 2020.

[43] D. Choi, W. Yoo, G. Noh, and K. Park, "The impact of social media on risk perceptions during the MERS outbreak in South Korea," Comput. Human Behav., vol. 72, pp. 422-431, 2017, doi: 10.1016/j.chb.2017.03.004.

[44] S. El-toukhy, "Parsing Susceptibility and Severity Dimensions of Health Risk Perceptions," J. Health Commun., vol. 20, no. 5, pp. 499-511, 2015, doi: 10.1080/10810730.2014.989342.

[45] G. Sharifirad, P. Yarmohammadi, M. Ali, M. Sharifabad, and Z. Rahaei, "Determination of preventive behaviors for pandemic influenza $\mathrm{A} / \mathrm{H} 1 \mathrm{~N} 1$ based on protection motivation theory among female high school students in Isfahan, Iran,” J. Educ. Health Promot., vol. 3, no. January, pp. 36-41, 2014, doi: 10.4103/2277-9531.127556.

[46] A. Bish, L. Yardley, A. Nicoll, and S. Michie, "Factors associated with uptake of vaccination against pandemic influenza: A systematic review," Vaccine, vol. 29, no. 38, pp. 6472-6484, 2011, doi: 10.1016/j.vaccine.2011.06.107.

[47] M. Bults et al., "Perceived risk, anxiety, and behavioural responses of the general public during the early phase of the Influenza A (H1N1) pandemic in the Netherlands: results of three consecutive online surveys," BMC Public Health, vol. 11, no. 1, pp. 1-13, 2011.

[48] N. Mahfuza, R. A. Syakurah, and R. Citra, "Analysis and potential use of google trends as a monitoring tool for risk communication during COVID-19 pandemic," International Journal Public Health Science(IJPHS), vol. 9, no. 4, pp. 399-405, 2020, doi: 10.11591/ijphs.v9i4.20512.

[49] L. Amelia and R. A. Syakurah, "Analysis of public search interest towards immune system improvement during the COVID-19 pandemic using google trends," International Journal Public Health Science(IJPHS), vol. 9, no. 4, pp. 414-420, 2020, doi: 10.11591/ijphs.v9i4.20518.

[50] M. Chandra and R. Syakurah, "Potential use of personal protection online search during COVID-19 pandemic for predicting and monitoring public response," International Journal Public Health Science(IJPHS), vol. 9, no. 4, pp. 406-413, 2020, doi: 10.11591/ijphs.v9i4.20547.

[51] P. Babcicky and S. Seebauer, "Unpacking Protection Motivation Theory: evidence for a separate protective and non-protective route in private flood mitigation behavior Unpacking Protection Motivation Theory: evidence for a separate protective and non-protective route in private flood," J. Risk Res., vol. 22, no. 12, pp. 1503-1521, 2019, doi: 10.1080/13669877.2018.1485175. 